\title{
A EDUCAÇÃO E SEU PAPEL MOBILIZADOR PARA O DESIGN ORIENTADO À QUALIFICAÇÃO DO CENÁRIO URBANO COMO ESPAÇO DE CONVIVÊNCIA
}

Profa. Dra. Marli Teresinha Everling

Universidade da Região de Joinville, UNIVILLE, SC meverling@gmail.com

Profa. Dra. Adriane Shibata Santos

Universidade da Região de Joinville, UNIVILLE, SC e-mail do segundo autor

Profa. MSc. Anna Luiza Moraes de Sá Cavalcanti Universidade da Região de Joinville, UNIVILLE, SC anna.cavalcanti08@gmail.com

Profa. Dra. João Eduardo Chagas Sobral Universidade da Região de Joinville, UNIVILLE, SC Sobra141@gmail.com

Prof. Esp. Luis Eduardo Souza

Universidade da Região de Joinville, UNIVILLE, SC dudu1803@gmail.com

Prof. Esp. Irma Haench

Universidade da Região de Joinville, UNIVILLE, SC irma.haensch@gmail.com

Bca. Allysson Thiago da Cruz

Universidade da Região de Joinville, UNIVILLE, SC allyson.cruz@,formus.com.br

Prof. Esp. Sidnei Zamberlan Universidade da Região de Joinville, UNIVILLE, SC sidneiz@gmail.com 
Resumo: A educação no campo do design pode ser orientada para a preparação de recursos humanos, não apenas para as indústrias e o desenvolvimento de produtos e serviços, mas para o setor público e a qualificação do espaço urbano. Considerando os inúmeros desafios associados ao cenário urbano, este artigo objetiva relatar as ações desenvolvidas no curso de pós-graduação em design da Universidade da Região de Joinville (Univille). O relato apresenta os fundamentos educacionais e contextuais que nortearam a construção da proposta do Mestrado em Design, considerando também o ambiente urbano e atividades nele desenvolvidas. Por fim, apresenta os resultados obtidos.

Palavras-chave: Educação, Design, no contexto urbano.

\begin{abstract}
Education in design field can be a good way to prepare human resources, not only to the industries and product development process, but also to the public sphere and the improvement of the urban environment. Considering the challenges associated to the urban scenario, this approach aims to describe the actions related to that goal by the Post-Graduation Course in Design offered by University of Joinville Region (Univille). The paper presents the contextual and educational bases of the Mastership Course in Design concerning the urban environment and finishes presenting the results.
\end{abstract}

Palavras-chave: Education, Design, Urban Context.

\title{
1. INTRODUÇÃO
}

O estudo, cujo relato aqui se apresenta, iniciou com a configuração do curso de Pós-Graduação em Design na Univille (Universidade da Região de Joinville) no ano de 2012, ocasião em que o curso de graduação em Design da instituição completava 14 anos, oferecendo linhas de formação em Projeto de Produto, Programação Visual, Animação Digital, Moda e Interiores somando mais de 40 turmas. A partir da massa crítica formada, foi estruturada e aprovada a proposta do Mestrado Profissional em Design da Univille. No mesmo ano, a CAPES (Coordenação de Aperfeiçoamento de Pessoal de Nível Superior) publicava o resultado do seminário promovido por ela com foco no papel da pós-graduação e os desafios da gestão urbana.

Percebeu-se, neste documento, a possibilidade de alinhar a proposta de Mestrado com estes resultados. Dos seis painéis realizados ao longo deste seminário da CAPES, três foram analisados em maior profundidade pela sincronia com as intenções da estruturação do mestrado. Esta análise é aprofundada ao longo do artigo, bem como o processo de construção da proposta e as articulações relacionadas ao contexto urbano pelo curso de Mestrado, em especial o LECid (Laboratório de Estudos em Design-Cidade). Os documentos usados para a análise consistem na publicação dos resultados do Seminário realizado pela CAPES e na Proposta do Curso de Mestrado. Antes desta análise é apresentada a discussão do papel da Educação e do Design para a Qualificação do Espaço Urbano apoiada em autores da área da educação, do design, urbanismo e sustentabilidade. Os principais autores da área da educação são Freire, 
Fagundes (1985) e Dewey (2004); já os principais autores relacionados a design, urbanismo, meio ambiente e questões urbanas são Jacobs (1961), Manzini e Vezzoli (2002), e, Leite (2012).

Os resultados apresentam algumas ações conduzidas no âmbito da graduação e da pós-graduação em Design da Univille com algumas organizações, orientadas para qualificação do cenário urbano como espaço de convivência.

\section{O PAPEL DO DESIGN PARA A QUALIFICAÇÃO DO ESPAÇO URBANO}

Autores que discutem o Design Urbano convergem em suas abordagens ao considerar que se trata de um campo interdisciplinar e complexo, que envolve corresponsabilidade (LERNER, 2007, web), colaboração (CARMONA et al. 2010, WEB), planejamento (TIBBALDS, web) e equilíbrio entre tecnologia e valores sociais (GOLANY, 1995). Para a Socióloga Inaê (2003 apud BRANCAGLION, 2006, p. 32), a cidade é

[...]mais do que um fato arquitetônico ou geográfico [a] cidade é um fenômeno social, uma produção - e também uma produtora - das atividades coletivas humanas. Mais que o conjunto das edificações e vias, a cidade é o lar de cada um de seus moradores, é aquele espaço social único no mundo porque abriga as vias individuais e os menores núcleos da vivência social.

O entendimento da cidade como um cenário coletivo, no qual se desenrola a vida cotidiana (considerando a circulação, educação, recreação, trabalho e habitação), e a investigação de comportamentos e demandas relacionadas às relações de uso no contexto urbano é que deverão orientar a identificação de produtos e serviços que podem contribuir com a dimensão social e coletiva da cidade, promovendo sua ocupação e o cuidado coletivo com o espaço.

Ao discutir os requisitos ambientais para o desenvolvimento de produtos industriais sustentáveis, Manzini e Vezzoli (2002) analisam oportunidades considerando o ciclo de vida dos produtos e, por este viés, apresentam o conceito integrado do desenvolvimento de produtos e serviços. Os autores partem da conversão de um cenário caracterizado pela oferta/consumo individual de produtos para um cenário de oferta integrada de produtos e serviços destinados ao uso coletivo, no qual a noção de compartilhamento substitua a relação de propriedade. Os autores caracterizam o design de serviços como uma proposta de superação do paradigma do produto, ou seja:

[...] do projeto centralizado unicamente em um bem físico. Isto é, propomos uma mudança do conteúdo de projeto com a extensão que vai do produto ao serviço e deste ao sistema de comunicação. Nesta perspectiva, não é suficiente projetar apenas os valores estético-formais, funcionais e de serventia de um produto. É também necessário projetar a forma das relações entre as diversas pessoas e entre estas pessoas e os produtos. Em outros termos, é necessário operar, no espaço e no tempo aonde a interação venha acontecer; temos que compreender a razão da interação, para projetarmos o modo como isto deva acontecer e o conteúdo físico e cultural onde vai acontecer (MANZINI, 1995, apud MANZINI E VEZZOLI, 2002, p. 274). 
Neste sentido, observa-se um amplo campo de ação por parte do design e de áreas afins, que podem trabalhar ações e soluções para as necessidades emergentes das cidades, contribuindo para a construções de cidades sustentáveis. De acordo com Leite (2012, p. 8):

[...]a reinvenção das metrópoles contemporâneas, no século 21, passa pelos novos indicadores que mostram oportunidades em termos de cidades mais sustentáveis e mais inteligentes do que as que cresceram e se expandiram sem limites no século 20. 0 desenvolvimento sustentável é o maior desafio do século 21. A pauta da cidade é, no planeta urbano, da maior importância para todos os países pois: (a) dois terços do consumo mundial de energia advêm das cidades e (c) vive-se um processo dramático de esgotamentos dos recursos hídricos e de consumo exagerado de água potável. A agenda cidades sustentáveis é, assim, desafio e oportunidade únicas no desenvolvimento das nações.

Ainda de acordo com o autor, o enfoque em cidades mais verdes pode e deve passar pela reinvenção das metrópoles, como mostram as experiências de Barcelona, Vancouver, Nova York, Bogotá e Curitiba.

A abordagem do Programa UN-Habitat para o planejamento urbano e o design foca em soluções para que as pessoas e os lugares estejam juntos, estruturando as cidades de forma a valorizar a acessibilidade. Em outras palavras, os habitantes da cidade devem ser capazes de atender às suas necessidades no seu entorno, evitando grandes deslocamentos. Para isso, toda uma estrutura de produtos e serviços precisam ser planejados em quarteirões ou bairros autossuficientes, evitando o uso do automóvel e promovendo a utilização de meios de transporte menos poluentes, incentivando a caminhada, trazendo o cotidiano para a escala do perceptível, do vivencial. Nesta escala, é possível perceber a infraestrutura, o funcionamento da cidade, a qualidade dos espaços urbanos, a rede de relacionamentos dos usuários, etc.

$O$ enfoque nas relações de uso das pessoas com a cidade é um excelente ponto de partida para abordagens do design no contexto urbano. Neste sentido, O'Dolan (web) relata um estudo de caso que visava reduzir o uso do transporte individual na cidade de Londres. Em 2003 a cidade investiu no sistema de transporte coletivo. Este investimento massivo resultou em multidões usando sistemas de ônibus e metrôs.

Em investigação realizada pela organização Research Business international, $66 \%$ responderam que considerariam caminhar após realizar uma consulta a um mapa de caminhadas. Com base nestes estudos foram desenvolvidos 19 mapas de navegação pelas ruas e um projeto de sinalização foi implantado em áreas de circulação massiva, visando auxiliar residentes e visitantes a alcançar seus destinos de forma segura e rápida. Em adição, mapas foram colocados em pontos de ônibus e estações de metrô. Observa-se assim, que por meio de ações simples de design, mas propostas a partir de pesquisas preliminares, pode-se contribuir com a melhoria dos espaços urbanos.

Manzini e Vezzoli (2002) sintetizam o papel do design como a atividade que, ligando o tecnicamente possível com o ecologicamente necessário, faz nascer novas propostas que sejam social e culturalmente apreciáveis. As questões relativas ao desenvolvimento das cidades sustentáveis e à preservação do ecossistema estão em 
evidência no mundo contemporâneo. As eminentes ameaças ao meio ambiente exigem da atividade de projeto, nas suas mais diversas especialidades, uma reformulação e nova postura dos profissionais envolvidos, e a educação para a sustentabilidade é um caminho para a sensibilização, conscientização e ação.

\section{O PAPEL DA EDUCAÇÃO}

A discussão das possibilidades de abordagem de produtos e serviços, considerando o design e/ou o contexto urbano no âmbito educacional da graduação e da pós-graduação, contribuem para a qualificação do espaço urbano na medida em que orientam os profissionais e futuros profissionais a articular e contextualizar saberes e a agir mutuamente com senso de responsabilidade em prol da cidade, em uma visão sistêmica, consciente da indissociável relação da teoria e prática, do conhecer e do agir como nos propunha Dewey (2004).

A cidade é feita de experiências, e, neste espaço o homo urbis interage, produzindo suas escolhas, preferências e selecionando múltiplas formas de vivência. É um espaço de reflexão e conhecimento que gera continua reconstrução. "Experiência não é, portanto, alguma coisa que se oponha à natureza, - pela qual se experimente, ou se prove a natureza. Experiência é uma fase da natureza, é uma forma de integração, pela qual os dois elementos que nela entram - situação e agente - são modificados." (DEWEY,Idem, p. 13-14).

Partindo deste conceito, impõe-se a importância do processo educacional, pois a cidade, longe de ser uma realidade estanque, é permeável, corpo em constante transformação. Muda pelas vivências e experiências, pelo contato e pelo uso. É o espaço de incessante reflexão, onde a ação modificadora gera a transformação do agente. A cidade é portanto, o espaço onde se educa e se é educado, se vive e se é vivenciado, se reflete e se é refletido.

Este olhar voltado para a experiência, vivência e sensibilidade do cotidiano foi também o ponto de inflexão das abordagens voltadas para o urbanismo. Jane Jacobs (1961), jornalista e ativista política, usou em meados do século XX a observação, a vivência e a sua experiência cotidiana no contexto urbano para escrever 'Morte e Vida das Grandes Cidades', que representou um ponto de inflexão para o urbanismo, reivindicando o desenho da cidade com foco na dimensão humana. A valorização do cotidiano, das vivências, das experiências e da dimensão humana também estão presentes nas reflexões do urbanista Jan Gehl (2013), e da Jornalista Natália Garcia (web) sobre a cidade: ele, dinamarquês, é autor do livro 'Cidade para pessoas' e ela, brasileira, é autora do site 'Cidades para pessoas'. São três formadores de opinião que, com diferentes perspectivas profissionais centralizam sua discussão em estratégias para devolver a cidade para as pessoas, e para mantê-la viva, segura, sustentável e saudável.

Por ser processo transdisciplinar, a educação é melhor compreendida quando relacionada a outras tantas dimensões, e a cidade, como campo de estudo para o design, oportuniza o confronto entre o conhecimento técnico-cientifico, produzido na universidade, e as múltiplas dimensões do espaço coletivo. 0 processo de aperfeiçoamento é uma constante na vida humana, o que dá sentido e torna a educação tão indispensável. É por meio dela que o ser humano se constrói, cresce, amadurece e se aperfeiçoa. Pode-se dizer, em outras palavras, que a educação é uma 
atividade que visa à formação e ao aperfeiçoamento do ser humano, e a cidade é um espelho em todos os seus complexos.

A cidade se mostra um campo rico à experiência proposta em DEWEY (Idem) que propõe a ideia de experiência capaz de dar a mesma atenção que se tem para o que é "nobre, honroso e verdadeiro", também ao que na vida humana, existe de "desfavorável, precário, incerto, irracional e odioso". A experiência educativa passa a ser uma experiência reflexiva que propõe a reconstrução e reorganização da experiência no fazer e vivenciar o coletivo da cidade. "O homem é homem e o mundo é histórico-cultural na medida em que ambos inacabados, se encontram numa relação permanente, na qual o homem, transformando o mundo, sofre os efeitos de sua própria transformação" (FREIRE,1985, p. 76).

Tanto Freire quanto Dewey concordam com a ideia do "aprender fazendo", da construção do aprendizado no processo dialético da construção social, do trabalho cooperativo e na indissociabilidade da teoria e prática, a construção do ensino pela ação. A cidade, como campo de construção coletiva, produz instrumentalidades eficazes e facilita o apoderamento de saberes múltiplos. Dewey (Idem) observa que quando negligenciamos a conexão entre objetos científicos e acontecimento da experiência primária, gera-se um mundo de coisas indiferentes.

\section{A EDUCAÇÃO E SEU PAPEL MOBILIZADOR PARA O DESIGN ORIENTADO NA QUALIFICAÇÃO DO ESPAÇO URBANO}

Em 2012, ano da construção da Proposta do Curso de Mestrado em Design da UNIVILLE, foi publicado pela CAPES, o resultado do seminário promovido sob o título "A Metropolização Brasileira e os Desafios da Gestão Urbana - O Papel da PósGraduação". A relevância dos resultados deste seminário estava na intenção de nortear a política de indução da instituição, cooperando com o entendimento dos princípios de formação de recursos humanos qualificados.

Com a intenção de alinhar o Mestrado Profissional em Design da Univille com estas intenções, buscou-se no documento publicado do resultado do seminário, elementos que pudessem contribuir com a configuração de propostas de pesquisa e linhas de ação. Após avaliar os resultados apresentados nos seis painéis realizados ao longo do seminário, selecionaram-se aqueles que melhor se articulavam com os objetivos da proposta do curso, que se constituíram em seta de orientação para a elaboração de disciplinas para o mestrado; foram eles:

Quadro 1 - Abordagem dos painéis selecionados do seminário A Metropolização Brasileira e os Desafios da Gestão Urbana - O Papel da Pós-Graduação

\begin{tabular}{|l|l|}
\hline Painel & Abordagem \\
\hline Painel I & $\begin{array}{l}\text { Urbanização Contemporânea com discussões vinculadas as cidades brasileiras e suas } \\
\text { múltiplas dimensões com destaque para questões relacionadas à densidade } \\
\text { demográfica e sustentabilidade das cidades; verticalização versus orientação; } \\
\text { dispersão e fragmentação urbana; aspectos relacionados ao policentrismo urbano; } \\
\text { redes, hierarquias urbanas; formas de produção e apropriação dos espaços urbanos; } \\
\text { e, olhar prospectivo para o futuro. }\end{array}$ \\
\hline Painel 2 & $\begin{array}{l}\text { Políticas, Planejamento e Gestão Urbana com questões relacionadas ao homem e a } \\
\text { atividade (circulação, recreação, trabalho, habitação) e sistemas que ofereçam } \\
\text { informação. }\end{array}$ \\
\hline Painel 3 & Habitação, Mobilidade e Acessibilidade Urbana com abordagens como cidades e
\end{tabular}




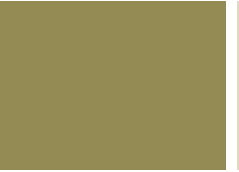

circulação de pessoas; o projeto como mediação da construção social da cidade; cidade, sociedade e gestão urbana; habitação e acessibilidade; abordagem social; e, criação de bases sólidas de sistemas de informação que possam apoiar a tomada de decisões.

Fonte: Elaborado pelos autores, com base em CAPES (2012)

Salienta-se que a consulta aos resultados do seminário contribuiu para a configuração das linhas de Pesquisa do PPGDESIGN e para o delineamento dos projetos de pesquisa associados ao mestrado.

Quadro 2 - Caracterização do curso de Mestrado Profissional em Design, considerando aspectos relacionados ao contexto urbano

PPGDESIGN: Mestrado Profissional em Design

Área de concentração: Design e Sustentabilidade - Compreende questões e aspectos relacionados ao design no contexto urbano em empresas de diversos segmentos industriais ou artesanais, com abrangências analítica, metodológica, de pesquisa aplicada e teórico-reflexiva. Considera as transformações sociais, culturais e tecnológicas, discutindo o papel dos profissionais que atuam neste contexto. O Programa objetiva o atendimento às demandas tecnológicas, sociais e de mercado, com foco na sustentabilidade.

Linha de Pesquisa 1 - Produção do Design e Contexto Sociocultural: Esta linha de pesquisa investiga as relações do design com a realidade social, considerando o contexto urbano, o mercado, o comportamento do consumidor, a sociedade, a cultura material e suas questões simbólicas e estéticas. Abrange a influência e ações do design na reprodução dos valores culturais e sociais, objetivando o desenvolvimento de produtos e serviços sustentáveis.
Linha de Pesquisa 2 - Produção Tecnológica e Sustentabilidade: Esta linha de pesquisa investiga questões direcionadas ao estudo das relações usuário-objeto e meio ambiente, considerando aspectos de interface, interações físicas e sustentabilidade. Abrange novas possibilidades em relação aos aspectos de desenvolvimento, produção e gestão do processo de design e do desenvolvimento de produtos e serviços.

Disciplina Design de Produtos e Serviços no contexto Urbano: aborda aspectos relacionados ao design de produto e de serviço como mediação da construção social da cidade. Abrange o design e dimensões materiais, sociais e ambientais na vida urbana, bem como o design de serviços e produtos no cenário de circulação, recreação, trabalho e habitação no contexto urbano. Objetiva investigar contribuições que o design de produto e serviço pode trazer considerando metrópoles, acessibilidade e mobilidade.

Fonte: Elaborado pelos autores, com base no site do curso.

Como instrumento de viabilização e fomento do Design Orientado para a Qualificação do Espaço Urbano, foram criados 3 projetos de pesquisa associados ao estudo do contexto urbano.

Quadro 3 - Projetos de Pesquisa do Mestrado Profissional em Design, considerando aspectos relacionados ao contexto urbano

\section{[D4SMOB] - Contribuições do design para o desenvolvimento sustentável de cidades: um estudo de caso em Joinville}

[URBE] O estudo das relações de uso e do contexto urbano como suporte ao design prospectivo de produtos e serviços na Cidade de Joinville.
Trabalha com o conceito de cidades inteligentes e visa identificar possibilidades do design para resolver problemas de mobilidade e acessibilidade urbana em médias e grandes cidades.

Objetiva a investigação do comportamento do usuário e a análise de suas atividades (circulação, educação, recreação, trabalho e habitação) no contexto urbano de Joinville como recurso para produção de informações de suporte ao design prospectivo de produtos e serviços com foco nas relações de uso dos espaços urbanos em Joinville. 
[REUSE] Investigação sobre o reuso dos resíduos industriais na região de Joinville: um olhar do design a partir da abordagem do upcycling.
Pretende investigar o descarte de resíduos industriais sólidos passíveis de reuso na região de Joinville, procurando compreender como esta prática vem sendo realizada em algumas empresas. O olhar do design tem por objetivo agregar valor a matéria-prima descartada, propondo novos usos.

Fonte: Elaborado pelos autores.

Com a articulação dos Projetos DS4MOB, URBE e REUSE foi criado o Laboratório de Estudos em Design-Cidade (LECid), que apresenta a seguinte estrutura:

Quadro 4 - Configuração do Laboratório de Estudos em Design-Cidade (LECid), considerando aspectos relacionados ao contexto urbano

Laboratório de Estudos em Design-Cidade [LECid]

Linha de Pesquisa: Comunicação Visual e Espaço
Urbano
Palavras-chave: Comunicação visual; intervenção
urbana; Sinalização de orientação e circulação
Objetivo: Enfatiza a importância da comunicação
visual nos centros urbanos e como eles podem
influenciar positiva ou negativamente estes
ambientes. Nesta abordagem, a comunicação
visual pode ser considerada uma ferramenta de
comunicação e de segurança nas cidades.

\footnotetext{
Linha de Pesquisa: Design e Sustentabilidade

Palavras-chave: Contexto urbano; design; sustentabilidade.

Objetivo: Propõe um investigação sobre os aspectos que envolvem a contribuição do design para a sustentabilidade no contexto urbano de Joinville, analisando possíveis melhorias nos produtos e serviços que envolvem o cidadão, considerando os impactos ambientais, sociais e econômicos.
}

\begin{abstract}
Linha de Pesquisa: Design, cultura e interrelações sociais

Palavras-chave: Design e cultura; Design e interrelações sociais; Design participativo

Objetivo: Concentrar informações sobre cidade, utilizáveis em estudos de design destacando multidisciplinaridade e as interações sociais com a cidade e espaços como produtores de sentido. Observar e identificar linguagens artísticas, arquitetônicas e design e sua relevância. Os recursos utilizados abrangem observação do contexto urbano numa abordagem colaborativa e o estudo da relação entre a cidade, questões culturais e auto-percepção dos cidadãos.
\end{abstract}

Linha de Pesquisa: Mobilidade Urbana
Palavras-chave: cidades inteligentes e
sustentáveis; Design participativo; mobilidade e
acessibilidade urbana; produtos e serviços de
design.
Objetivo: Propõe estudos para identificar
possibilidades de design para problemas de
mobilidade e acessibilidade urbana em cidades de
médio e grande porte. Para isso, trabalha com o
conceito de cidades inteligentes.

Linha de Pesquisa: Relações de Uso
Palavras-chave: cidades inteligentes e sustentáveis; Contexto urbano; Design de produtos e serviços;
Design participativo; Mobilidade e acessibilidade; Relações de uso
Objetivo: Investigação do comportamento do usuário e análise de suas atividades (educação, recreação,
trabalho, habitação, mobilidade, acessibilidade, tecnologia, etc.) no contexto urbano de Joinville como
recurso para produção de informações de suporte ao design prospectivo de produtos e serviços com
foco nas relações de uso dos espaços urbanos.

Fonte: Elaborado pelos autores, com base nas propostas de cada pesquisa.

Com a estruturação do LECid, percebeu-se a possibilidade de ampliar a sua atuação para além da organização das atividades de ensino, pesquisa e extensão associadas à qualificação do espaço urbano no âmbito do mestrado. Assim, a proposta foi aberta também para professores e alunos da graduação em design e outras áreas. 
Atualmente a equipe conta com 5 pesquisadores e 10 alunos, sendo 5 do Mestrado Profissional em Design e 5 da graduação em Design. Paralelamente está em processo um movimento de aproximação com organizações já instituídas que possuem objetivos similares ao do LECid, como o Instituto de Pesquisa e Planejamento para o Desenvolvimento Sustentável de Joinville - IPPUJ, Instituto Caranguejo de Educação Ambiental, Núcleo de Gestão Ambiental da Associação Comercial e Industrial de Joinville ( $\mathrm{ACl}$ ) e Movimento Pedala Joinville (MPL).

O foco deste laboratório é a organização de informações que possam orientar um olhar participativo, colaborativo e multidisciplinar sobre a cidade e promover a interação social neste espaço, considerando a produção de sentidos no âmbito do design, arte, cultura e urbanismo. O laboratório foi estruturado a partir da percepção da necessidade de entendimento dos problemas relacionados à cidade de Joinville e da necessidade de qualificar produtos e serviços que apoiem as atividades associadas à mobilidade, ao lazer, trabalho, entre. Dentre os resultados alcançados até o momento, destacam-se: estruturação conceitual e organizacional do laboratório; estruturação de seminário multidisciplinar com foco nos desafios da cidade de Joinville e diversos projetos no âmbito da graduação e da pós-graduação.

De acordo com a proposta de criação do curso do Mestrado Profissional em Design, "a capacitação constante dos recursos humanos é um desafio coletivo que envolve a todos (...) e a sustentabilidade das cidades está relacionada à criatividade nas soluções dos problemas estruturais, da mobilidade, da acessibilidade, dos espaços públicos, da qualidade de vida urbana, de forma que as atividades de projeto contribuem com uma visão holística e centrada no usuário". Portanto, a abordagem da sustentabilidade em design, uma das linhas mestras do curso tem por objetivo capacitar os alunos para as questões que envolvem o desenvolvimento de produtos e serviços no contexto urbano, além da gestão do processo de design.

\section{RESULTADOS ALCANÇADOS}

A abordagem de questões relacionadas ao contexto urbano no Mestrado Profissional em Design tem repercutido no desenvolvimento de projetos de pesquisa, trabalhos de conclusão de curso (do mestrado e da graduação) com este enfoque, no desenvolvimento de projetos de iniciação científica (PIBICs), na absorção de discussões com esta abordagem pelo corpo docente e discente do curso de graduação em design e na extensão. Considera-se que pelo caráter universitário da Univille, o papel da educação transcende o ensino e se realiza também por meio da pesquisa e da extensão.

Uma das pesquisas em andamento no Mestrado Profissional em Design visa desenvolver o projeto de sinalização para rota segura já mapeada pela defesa civil de Joinville, orientando usuários em situações de alagamento que, devido às condições geográficas, são frequentes na cidade.

Os Projetos URBE e DS4MOB, associados ao programa de mestrado, além de uma intensa articulação entre si, repercutem também na graduação por meio de projetos de iniciação científica com estudantes e com a comunidade local.

O Projeto URBE desdobrou-se em dois projetos de iniciação científica (PIBIC) e um Trabalho de Conclusão de Curso (TCC). O primeiro projeto aborda o terminal urbano central e investiga potencialidades de produtos e serviços decorrentes das relações de uso das diferentes categorias de usuários (ciclistas, pedestres, etc) 
estabelecidas com o entorno e as adjacências. O segundo projeto de PIBIC pesquisa aspectos relacionados a percepção da cidade por meio da fotografia. Já o TCC desenvolvido por uma estudante de design objetiva produzir uma animação para o Movimento Pedala Joinville visando apoiar atividades educativas com foco na convivência e na gentileza de diferentes modais.

Com relação ao DS4MOB, estão em andamento dois projetos de iniciação científica (PIBITI/CNPq e bolsa institucional), um TCC e um projeto do Programa Institucional de Bolsas de Pós-Graduação stricto sensu (PIBPG). O PIBIT/CNPq está considerando a aplicação e usabilidade de interfaces em aplicativos para mobilidade urbana na cidade de Joinville; o projeto institucional e o PIBPG estão considerando situações de mobilidade urbana também nesta cidade, para posterior definição de demandas de projetos nas áreas de comunicação visual e sinalização e produtos/serviços, respectivamente. Já o TCC propõe uma solução conceitual de veículo com configuração de triciclo para uso urbano.

Como destacado anteriormente, além destas ações com foco em pesquisa e ensino, os dois projetos também trabalham ações de extensão em uma comunidade local por meio do projeto Criar \& Crescer, que utiliza junto a crianças do ensino básico, metodologias como o Design Participativo e Design for Change para promover mudanças positivas no espaço coletivo urbano do bairro.

O Projeto REUSE, também no âmbito do mestrado está em andamento uma pesquisa sobre o reuso dos resíduos industriais na região de Joinville: um olhar do design a partir da abordagem do upcycling. A pesquisa investiga o descarte de resíduos industriais sólidos passíveis de reuso, procurando compreender como esta prática vem sendo realizada. $O$ olhar do design tem por objetivo agregar valor à matéria-prima descartada, propondo novos usos. Dois bolsistas estão integrados nesta investigação, um graduando em design, pesquisando sobre a contribuição do design em iniciativas de upcycling no Brasil e no mundo, procurando entender o arranjo produtivo e o resultado do trabalho, assim como o tipo de produto e os benefícios para os atores envolvidos; e um mestrando pesquisando sobre os resíduos ferrosos e seu reaproveitamento em um sistema de calefação e cocção destinado a ambientes comunitários. O reuso do resíduo industrial sob a ótica do design pode transforma-se em novos produtos com características particulares, inovadoras, promovendo a valorização de grupos criativos na produção dos mesmos e minimizando os impactos ambientais no meio urbano dos resíduos produzidos pela cidade.

Além disso, também em termos educacionais, a equipe do Mestrado Profissional em Design produz conteúdo (com foco no contexto urbano e no meio ambiente) destinado para o público infanto-juvenil no Almanaque Ambiental Menino Caranguejo por meio da parceria estabelecida com $\mathrm{O}$ Instituto Caranguejo de Educação ${ }^{1}$, conforme destacado na Figura 1. Dentre os temas abordados destacam-se água, saúde \& conservação do solo, terra, comportamento \& consciência ambiental, biodiversidade, voluntariado e saneamento básico.

Figura 1 - Versão online do Almanaque número 13 que apresenta conteúdo produzido pelo programa de mestrado.

\footnotetext{
${ }^{1}$ http://www.caranguejo.com/homepage
} 


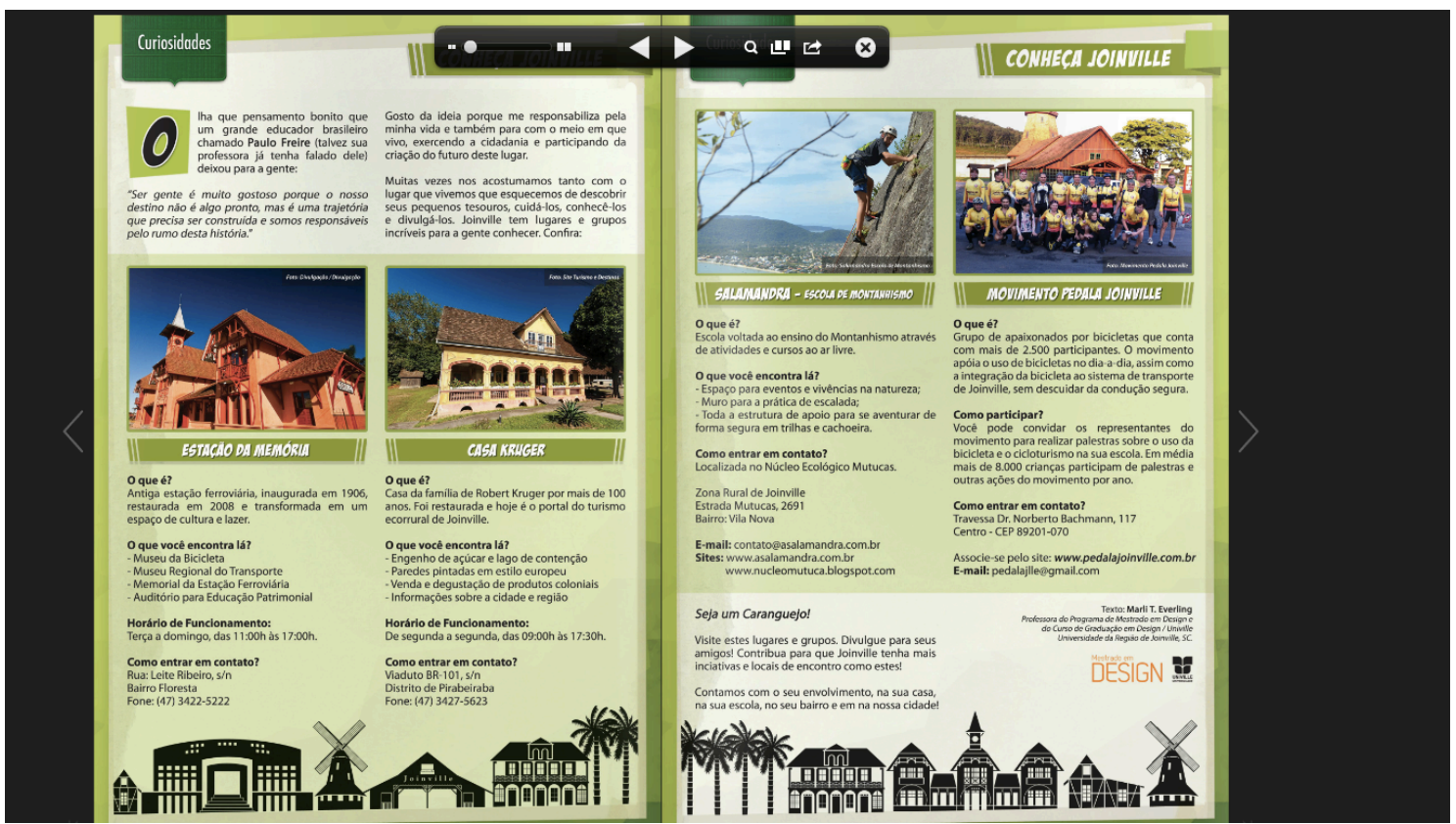

Fonte: Instituto Caranguejo de Educação Ambiental (web)

\section{CONCLUSÃO}

Observa-se que o crescimento populacional das cidades vem aumentando a cada ano e as possibilidades que estas oferecem indicam que cada vez mais as pessoas irão se aglomerar nos centros urbanos. Da percepção deste problema derivam discussões acerca do modo de vida nos ambientes urbanos destacando-se sua caracterização como espaços de convivência.

$\mathrm{O}$ artigo procurou apontar as diferentes possibilidades e lacunas existentes de pesquisas e ações, destacando o papel do design na reconfiguração do espaço urbano, não apenas pelo viés da materialização da cidade, mas também no projeto de serviços ou programas que favoreçam a sua ocupação também para o lazer, entre outras atividades.

Procurou ressaltar também o papel mobilizador da educação e o valor da experiência e da vivência da cidade pelos alunos (graduandos e mestrandos), preparando recursos humanos na área do design sensibilizados para os desafios urbanos.

Discorre também sobre a configuração do curso de Mestrado Profissional em Design da Univille com esta ênfase, destacando os diversos projetos em andamento ligados ao Laboratório de Estudos em Design-Cidade - LECid.

Acredita-se que os pontos marcantes do relato consistem na discussão de uma proposta educacional que transcenda os limites do mestrado, envolvendo instituições e organizações, contribuindo para um movimento mais amplo, envolvendo a comunidade científica e os cidadãos.

O investimento na formação de recursos-humanos capacitados para reflexões associadas ao contexto urbano e capazes de problematizar adequadamente questões relacionadas a este contexto repercutirá, no médio e no longo prazo, em contribuições do design para a qualificação do espaço urbano.

\section{REFERÊNCIAS}


BRANCAGLION, Ricardo Luiz. Equipamentos Urbanos, Design e Identidade Sóciocultural: Análise e Proposta para a Cidade do Núcleo Bandeirante no DF. Dissertação de Mestrado. Brasília: UNB. 2006.

CAPES. Seminário Internacional: A Metropolização Brasileira e os Desafios da Gestão Urbana - O Papel da Pós-Graduação. Maio de 2012. Disponível em: $<$ http://metropolizacao.capes.gov.br/index.php?option=com_content\&view=article\&i d=27\&Itemid=9>. Acesso em: 1 mar. 2013.

CARMONA, Matthew; TIESDELL, Steve; HEATH, Tim; OC Taner. Public Places - Urban Spaces: The Dimensions of Urban Design. (2a edição) Oxford : Elsevier. Disponível em: <http://books.google.com.br/books?hl=ptBR\&lr=\&id=GTQqshLjwCoC\&oi=fnd\&pg=PR1 \&dq=related:dKJIhsjFoQcJ:scholar.google.com/\&ots=isMUDuVByo\&sig=PluV1qG0OdZ0gp3J6KDaLZ_OYIIv=onepage\&q\&f=false>. Acesso em: 1 mar. 2013.

DEWEY, John. Democracia y Educacion. Madrid: Ediciones Morata, 2004.

FREIRE, Paulo; FAUNDEZ, Antônio. Por uma pedagogia da pergunta. 3a ed. Rio de janeiro: Paz e Terra, 1985.

GARCIA, Natália. Cidade para Pessoas. Disponível em http://cidadesparapessoas.com/ . Acesso em 13 maio 2014

GEHL. Jan. Cidade para Pessoas. Tradução Anita di Marco. São Paulo : Perspectiva. 2013 (1 $1^{\text {a }}$. Ed.)

GOLANY, Gideon S. Ethics \& Urban Design: Culture, Form \& Environment. New York : John Willey \& Sons. 1995.

INSTITUTO CARANGUEJO DE EDUCAÇÃO AMBIENTAL. Almanaque Ambiental Menino Caranguejo № 13. Disponível em: http://www.caranguejo.org.br/almanaqueambiental-13/. Acesso em 28 de abril de 2014.

JACOBS, Jane. Morte e Vida de Grandes Cidades. 1961 ( $1^{\text {a }}$ ed.). Tradução Carlos S. Mendes Rosa. São Paulo : WMF Martins Fontes. 2011 ( $3^{\mathrm{a}}$ ed.)

LEITE, Carlos, AWAD, Juliana di Cesare Marques. Cidades Sustentáveis, cidades inteligentes: Desenvolvimento Sustentável no planeta urbano. Porto Alegre. Ed. Bookman, 2012

LERNER, Jaime. O Canto da Cidade. Ted 2007. Disponível em: <http://videosubtitle. tedcdn.com/talk/podcast/2007/None/JaimeLerner_2007-480p-pt-br.mp4>. Acesso em: 4 de mar. 2013.

MANZINI, Ezio; VEZOLLI, Carlo. O Desenvolvimento de Produtos Sustentáveis. São Paulo: EDUSP. 2002. 
O DOLAN, Catriona. Wayfinding system for pedestrians in London (UK). Disponivel em http://www.eltis.org/index.php?id=13\&lang1=en\&study_id=2025. Acesso em 13 jun. 2013

TIBBALDS, Francis. Making People Friendly Towns - Improving the Public Environment inTowns and Cities. Disponível em: <http://books.google.com.br/books?hl=pt$B R \& \mid r=\& i d=O H i g e E Y u x o g C \& o i=f n d \& p g=P R 3 \& d q=r e l a t e d: d K J I h s j F o Q c J: s c h o l a r . g o o g l e . c$ om/\&ots=aH2eRH_J_e\&sig=jG2aLo1PYO52bhCYQQ1tuOK_6rl\#v=onepage\&q\&f=false $>$. Acesso em:28 fev. 2013.

UNHABITAT, DISPONÍVEL EM: http://unhabitat.org/urban-themes-2/planning-and-design/, acesso em 7 de maio 2014

UNIVILLE. APCN do Curso de Mestrado Profissional em Design. Código da Proposta: 8123. Joinville, Maio de 2012.

VEZZOLI, C. Design de sistemas para a Sustentabilidade: teoria, métodos e ferramentas para o design sustentável de "sistemas de satisfação". Salvador: EDUFBA, 2010. 